\title{
Anterior Surface of the Epiglottis
}

National Cancer Institute

\section{Source}

National Cancer Institute. Anterior Surface of the Epiglottis. NCI Thesaurus. Code C12238.

The lingual or upper surface of the epiglottis. 